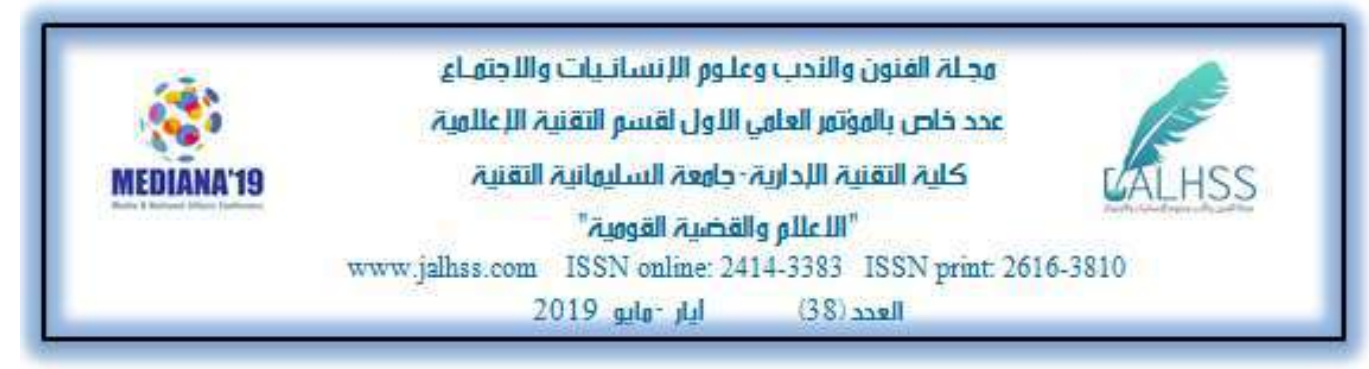

\title{
أثر وسائل الاعلام في بناء الهوية الثقافية لطلبة المرحلة الابتدائية في العراق
}

\author{
المدرس المساعد \\ نور خضير بلد \\ المديرية العامة لزبية محافظة بغداد الكرخ الاولى لبر

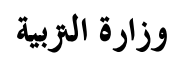

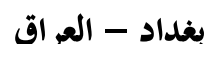

الحلاصة

تعتبر مسألة بناء او الحفاظ او تعزيز الهوية الثقافية عن طريق الإعلام ذات اهمية بالغة شديدة الحساسية بنفس الوقت. كما تمثل

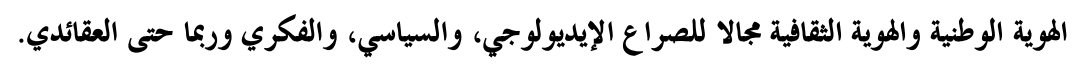

فالهوية الثقافية حقل ملغوم، وكذلك الهوية الوطنية وتعتبر مسألة جدلية بامتياز تتجاذبها ثنائيات الأصالة، والمعاصرة، والماضي، والحاضر،والانغلاق، والانفتاح، وتتصارع تيارات كثيرة على شرعية تحديد مضمونها.

و قد جاءت هذه الدراسة لتبين واقع المشكلة عندما نضع الإعلام قبل الهوية الوطنية او الثقافية ونناقش تأثيراتهما على طلبة

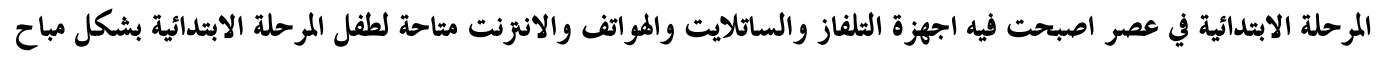
ودون أي مرشحات لما يمكن ان تععرض له الفكار هذا الطالب.

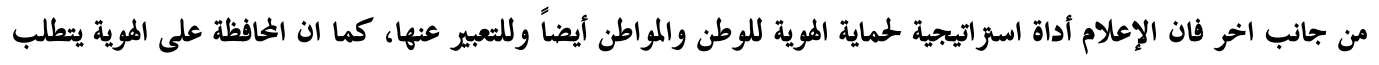

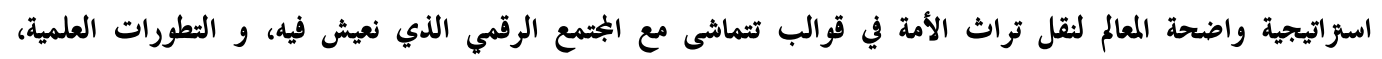
والنكنولوجية التي يشهدها البختمع.

لنتوصل في نهاية دراستنا هذه إلى ضرورة بناء نموذج خاص او توليفة فريدة تخص بالإعلام الموجه لطالب المرحلة الابتدائية وفي

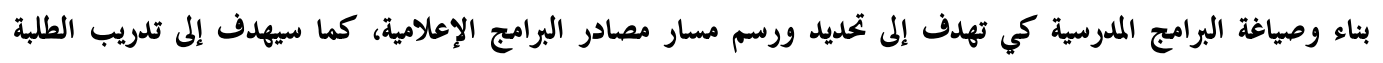
وتحفيزمم الى قراءة المضامين الإعلامية، و قبول فكرة تعدد معانيها، و تعزيز القدرة على الملى التفكير الذاتي. 


\title{
The Impact of Media in Building the Cultural Identity of Primary School Students in Iraq
}

\author{
Assistant Lecturer \\ Noor KhudairBadr \\ Ministry of Education \\ Baghdad - Iraq
}

\begin{abstract}
The issue of building, maintaining or promoting cultural identity through the media is of extreme importance at the same time. National identity and cultural identity also represent an area of ideological, political, intellectual and even ideological conflict.

Cultural identity is a mined field, as well as national identity. It is a dialectical issue with distinction drawn by the dualities of originality, contemporarily, past, present, closure, and openness and many currents struggle over the legitimacy of determining their content.

This study came to illustrate the reality of the problem when we put the media before the national or cultural identity and discuss the effects on primary school students in an era where television, satellite, telephones and the Internet are available to the child of the primary stage in a way that is permissible and without any filters for what may be exposed to the ideas of this student.

On the other hand, the media is a strategic tool to protect the identity of the homeland and the citizen as well and to express it. The preservation of identity requires a clear strategy to transfer the nation's heritage in melds that are in line with the digital society in which we live and the scientific and technological developments witnessed by society.

At the end of this study, we need to build a special model or combination of information directed at the primary school student and in the construction and formulation of school programs to identify and map the sources of media programs. It will also aim to train students to read media content, and enhance the ability to selfreflection.
\end{abstract}




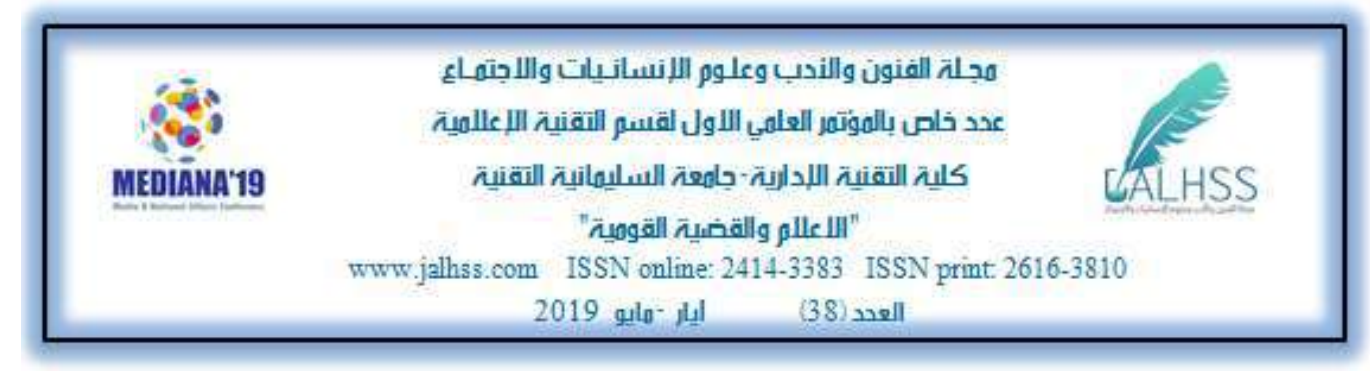

المبحث الاول: التعريف بالبحث ومنهجيته

مشكلة البحث

واجهت عملية الثدريس في المدارس في العراق ووزارة الزبية، تحديات كثيرة بغية تحقيق الرهانات التي تضطلع بها المدرسة من

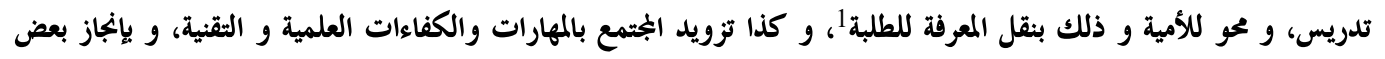

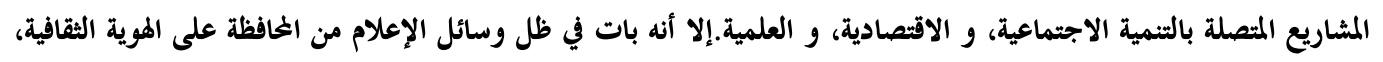
وغرسها في صفوف التلاميذ تدريييا حتى لا تضيع تلك المقومات.

أهمية البحث

لقد أحدثت وسائل الإعلام تغييرا جذريا في الفضاء الإعلامي، و أصبحت تنتشر كالفطر فتغلبت الرداءة، والذهنية التجارية على الرئ

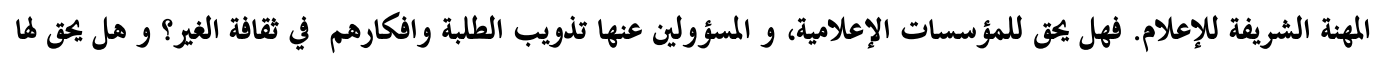
تهميش الهوية الثقافية والوطنية؟ أهداف البحث

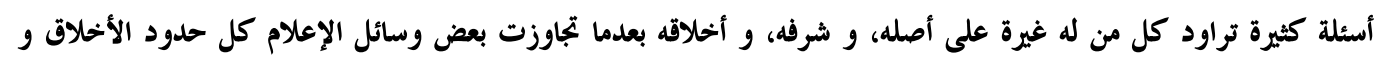

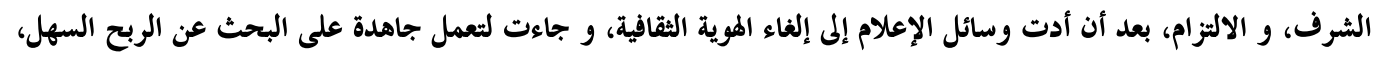

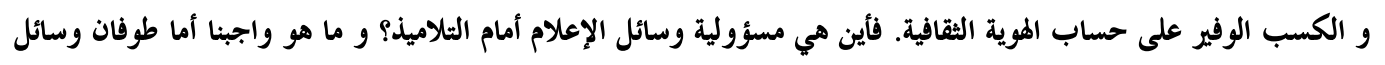

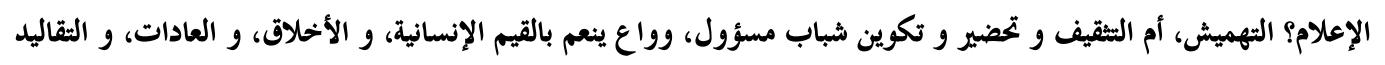

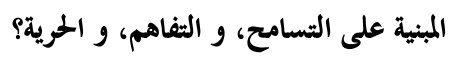

المبحث الثاني: تعريف الهوية الثقافية

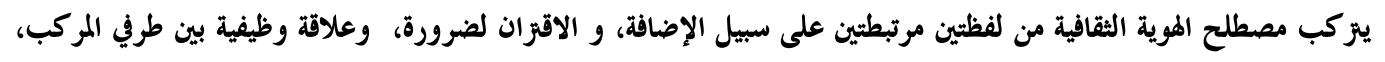

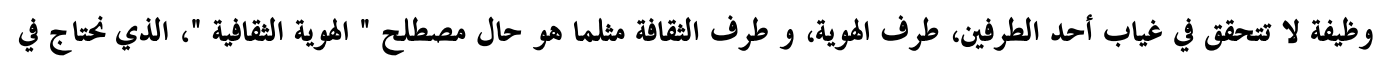

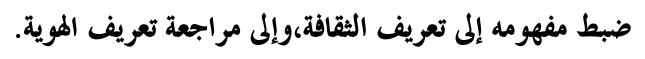




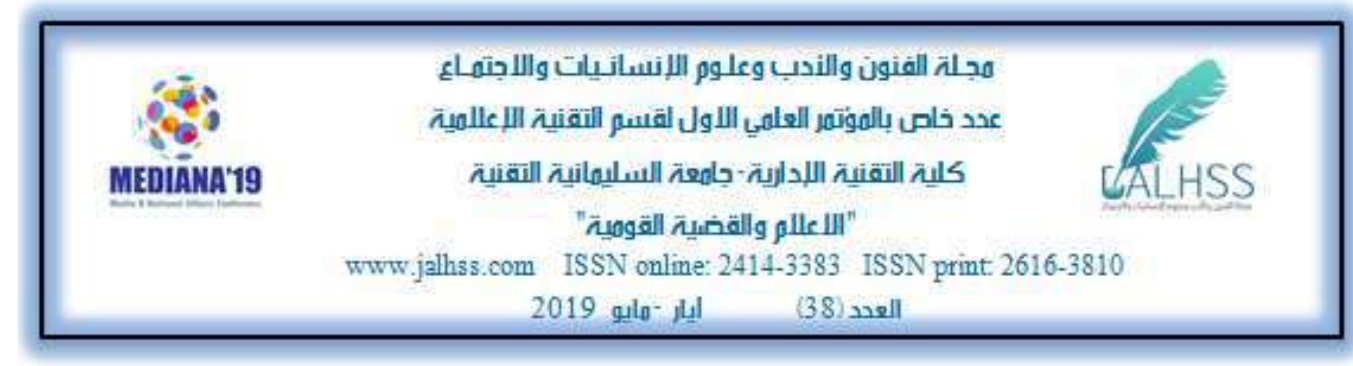

الفرع الأول: تعريف الثقافة لغة و اصطلاحا

أولا: الثقافة في اللغة

قعني كلمة " ثقف " في اللغة العربية " قوّم " الشيء" أي قومه عندما كان معوجا، و غير سوي، فقال العرب: " ثقفت الرمح أي

أي: جعله على أحسن صورة. و أيضا يأخذ هذا المصطلح معنى الإصلاح، و إعادة الشيء على حاله، و أيضا التصحيح.

ثانيا: الثقافة في الاصطلاح

أما في الاصطلاح فالثقافة هي ذلك الزاث الحضاري، و منهجية التفكير، و أسلوب العيش،و المعاملة، أي: تلك الأمور التي

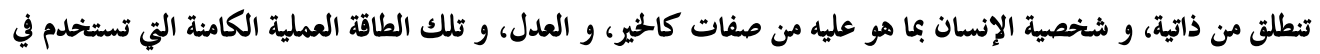

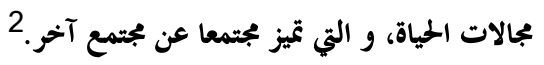
الفرع الثاني: تعريف الهوية لغة و اصطلاحا أولا: في اللغة يعني مصطلح " الهوية " الذات، و الأصل، و الانتماء، و المرجعية. و هي مأخوذة من كلمة " هو " أي: جوهر الشيء، و ثانيا: الهوية في الاصطلاح

تعرف " الهوية " على أنها الحقيقة المطلقة المشتملة على الحقائق اشتمال النواة على الشجرة في الغيب، أي تلك الصفة الثابتة، و

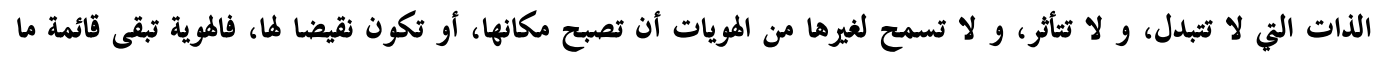

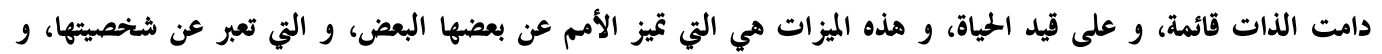
حضاراتها، و وجودها.4

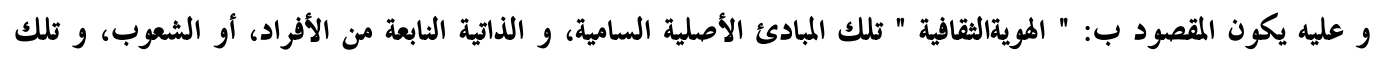

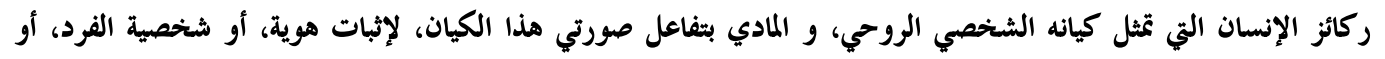

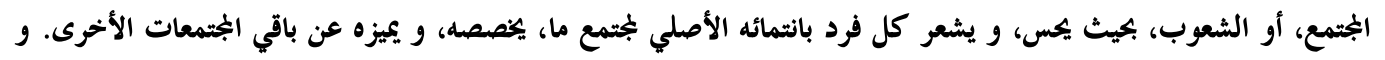
الهوية الثقافية تمثل كل الجوانب الحياتية الاقتصادية، والاجتماعية، والسياسية، والحضارية، والمستقبلية لأعضاء الجماعة الموحدة

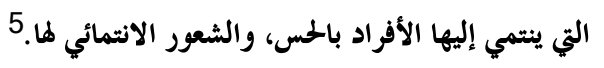
و أيضا هي ذاتية الإنسان و نقاؤه، و جمالياته، و قيمه، بحيث تعتبر الثقافة هي الخرك لأي حضارة، أو أمة في توجيهها، و ضبطها، أي هي التي تحكم حركة الإبداع، و الإنتاج المعرفي.6 


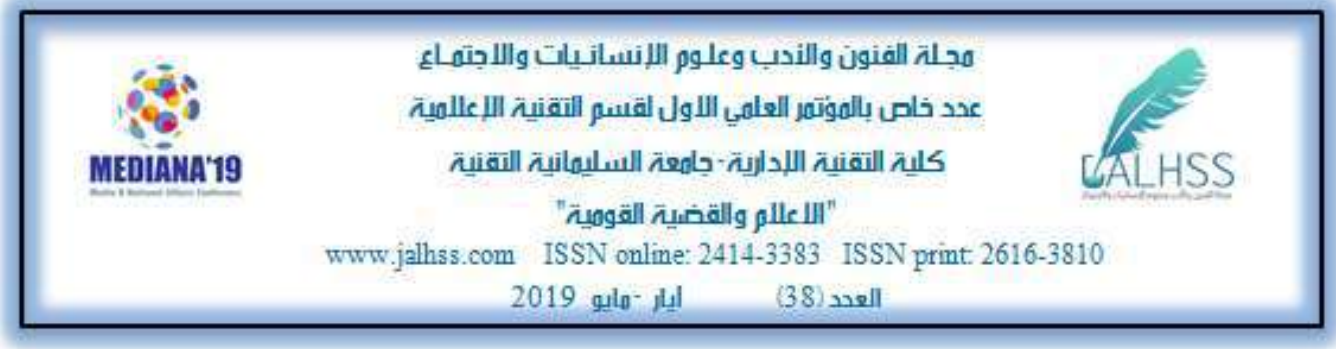

المبحث الثالث: آثار وسائل الإعلام على الهوية الثقافية للطلبة

يقصد بالإعلام: " هو فن استقصاء الحقائق، و المعلومات، و الأخبار، و معالجمتها، و نشرها على أوسع نطاق جماهيري، و في

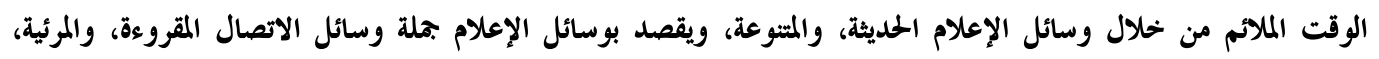
والمسموعة. "7

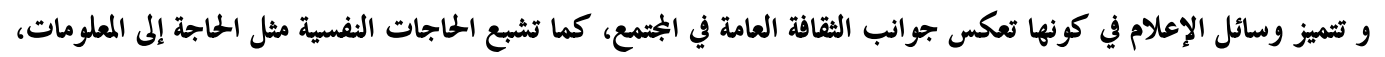

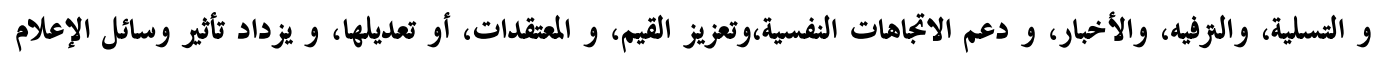

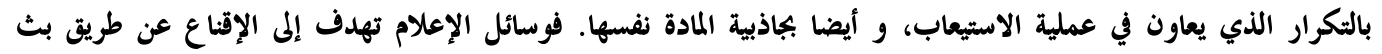

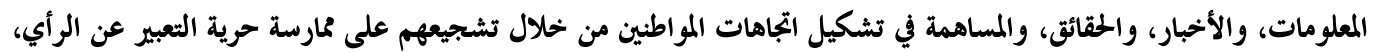

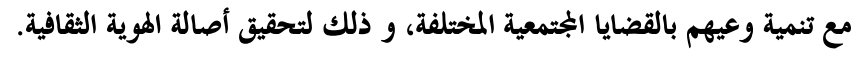
الفرع الأول: الآثار الإيجابية

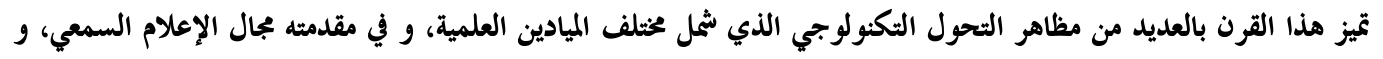

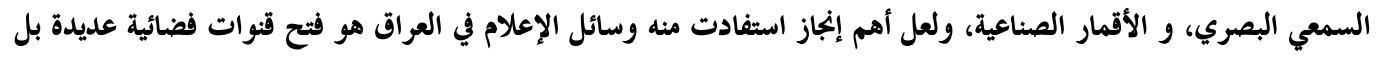

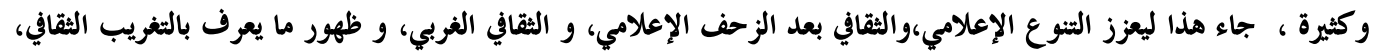

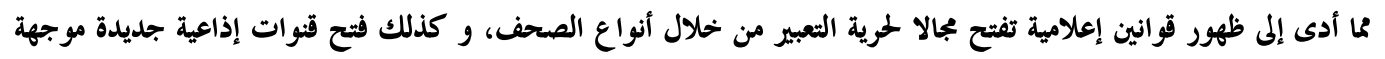

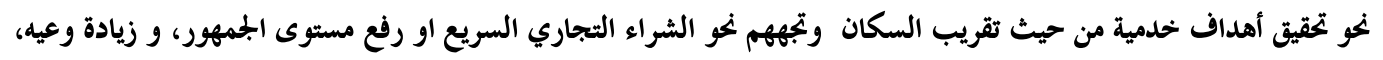

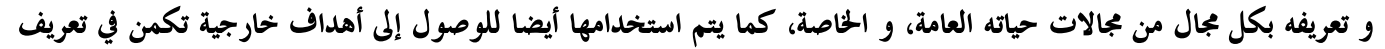
العالم بالحضارة، و تاريخ سكانها. وعليه تتجلى إيجابيات وسائل الإعلام على الموية الثقافية للطلبة فيما يلي: أولا: أصبحت الهوية الثقافية في ظل وسائل الإعلام نسبيا مزدهرة بإعطاء مكانة لها على المستوى المؤسساتي، و في ظل المناهج

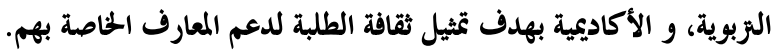
ثانيا: لوسائل الإعلام تأثير إيبابي بتحويل الشعور بالانتماء إلى حالة تعصب إلى حالة المرونة، والاعزاف بالغير في ظل الإنسانية بهدف القضاء على التعصب، و التشدد، و الجممود الفكري بين للطلبة في المرحلة الابتدائية.

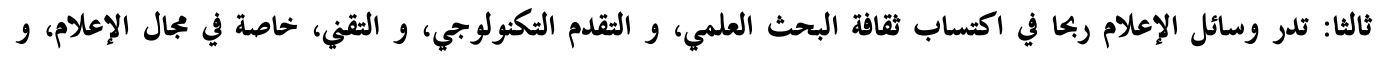

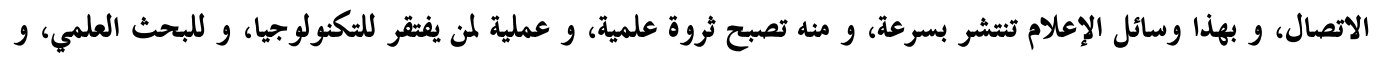




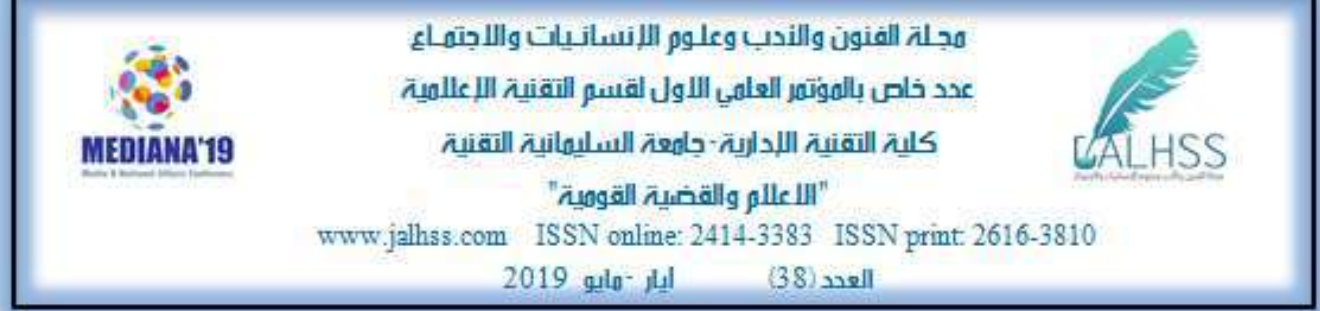

رابعا: تعد وسائل الإعلام بمثابة منبر للحوار، و التفتح الثقافي، و الاستفادة من ثقافة الغير، و لتكامل الثقافات، و بذلك يستفيد

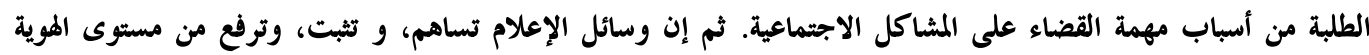

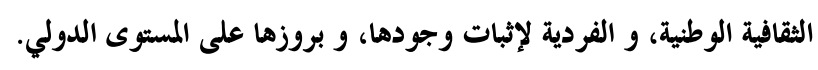

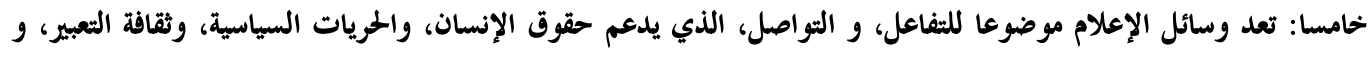

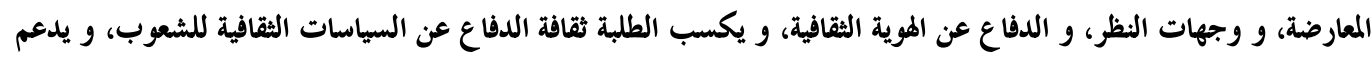

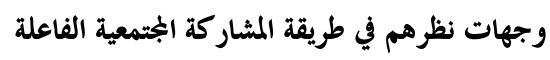

حيث إن وسائل الإعلام أدت إلى تطبيق ثقافة جديدة مفادها أن للفرد الحرية في اختيار أي الثقافات التي يراها مناسبة بهدف إبراز

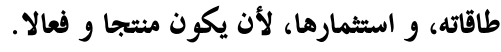
و خلاصة الآثار الإيجابية بالنسبة لوسائل الإعلام هي أن غرس الهوية الثقافية لدى الطلبة وتدفع بهم إلى التحرك و السير في

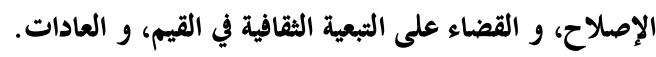

$$
\text { الفرع الثاني: الآثار السلبية }
$$

تتجلى المرجعيات الثقافية للهوية في تلك المنظومة من المعاير، و القيم، و المشاعر الأساسية، و التصورات التي تسمح بأن

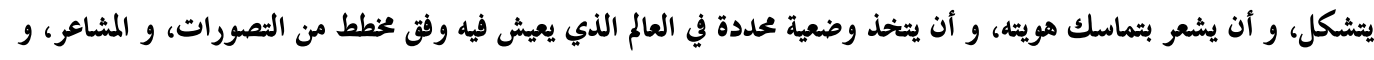

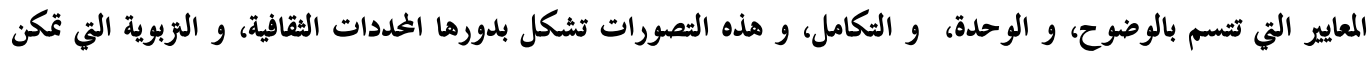

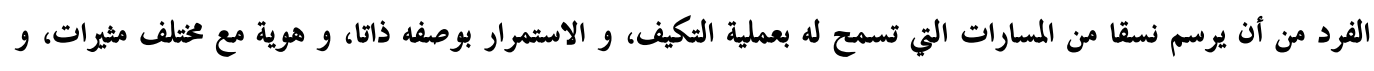

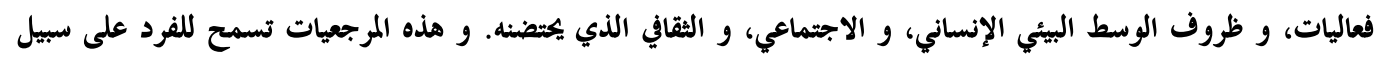

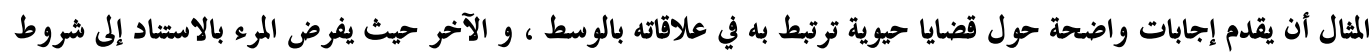

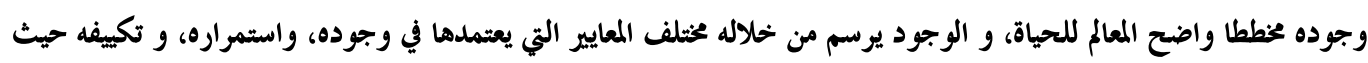

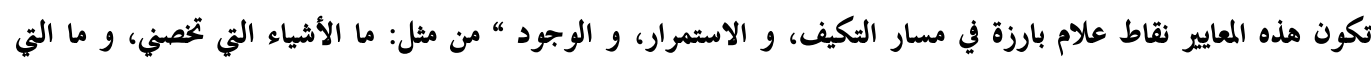

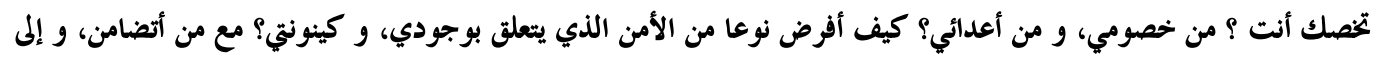

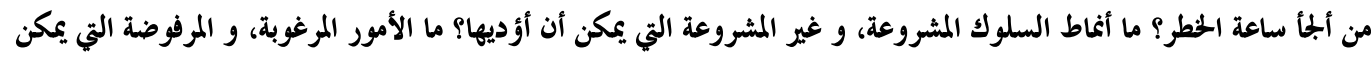

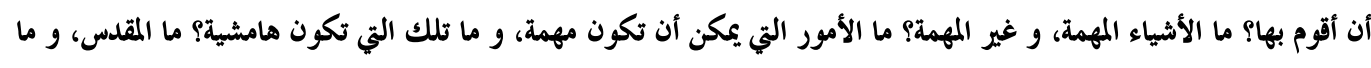

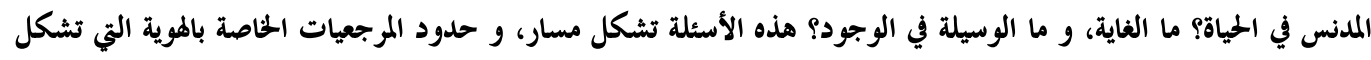
نواة الوجود، و الهوية،و الإحساس بالأنا، و التمايز، و النكوين.

و في هذا الخصوص يمكن القول بأن أي خلل، أو ضرر، أو تدمير يصيب هذه المرجعيات سيؤدي بالضرورة إلى عملية هدم اللهوية

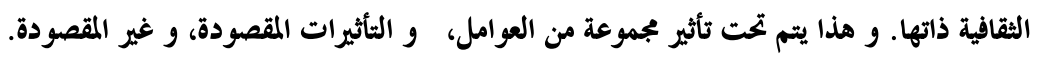




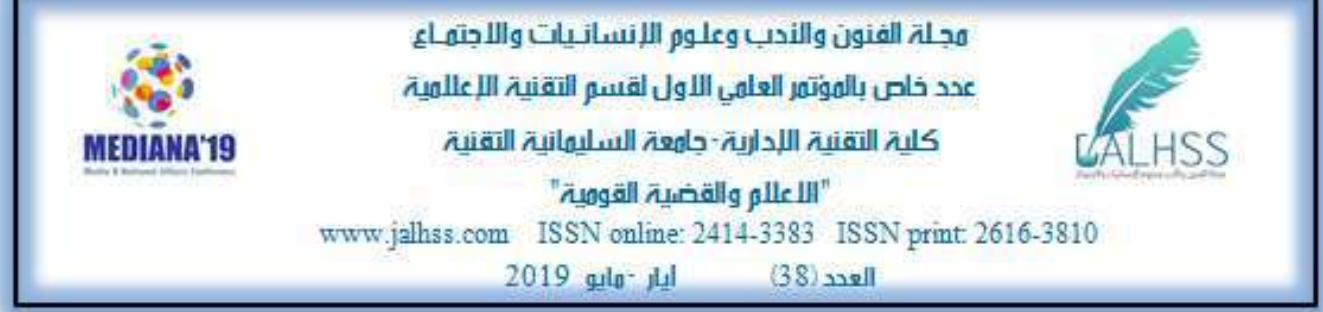

إن أساس سلبيات وسائل الإعلام على الهوية الثقافية للشعوب و الأفراد تكمن فيما قاله " صامويل هنتنجتون " إن الاعتقاد

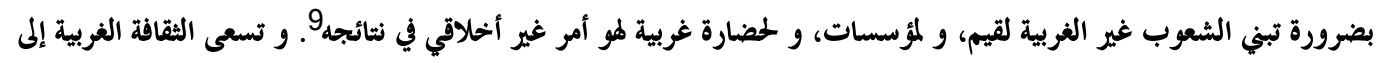

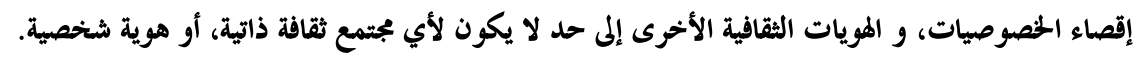

تثير وسائل الإعلام في العصر الراهن تغيرات عديدة في نمط الحياة، و في القواعد و القيم، والمعايير الاجتماعية، و الهوية الثقافية، و

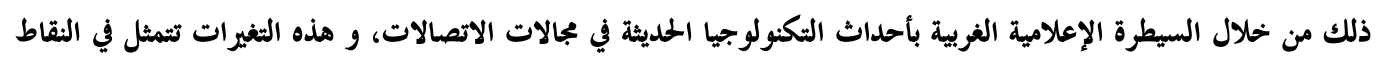
التالية:10:

أولا: الهيمنة الإعلامية الغربية ذات الطابع الغربي على وسائل الإعلام، و الاتصال، و تكنولوجيا المعلومات، فهذه الإمكانيات

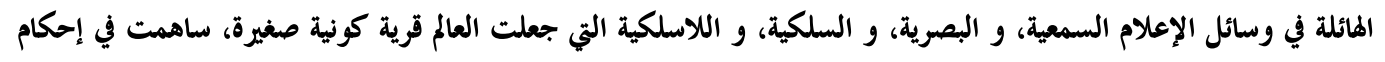

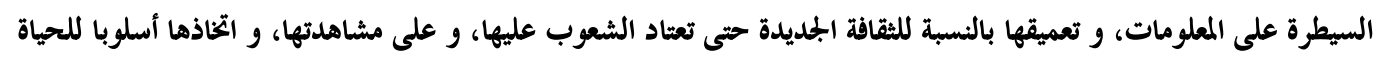
العصرية.

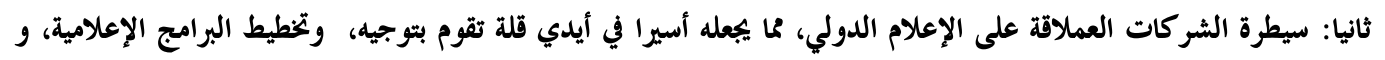

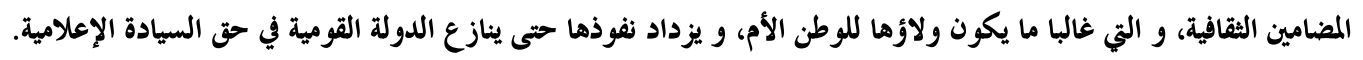

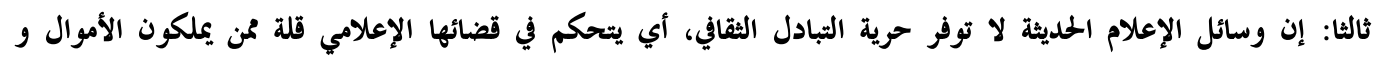
النكنولوجيا الحديثة، و يفرضون على الدول النامية ما يريدون نشره دون أن يتحقق حوارا الثقافيا متكافئا.

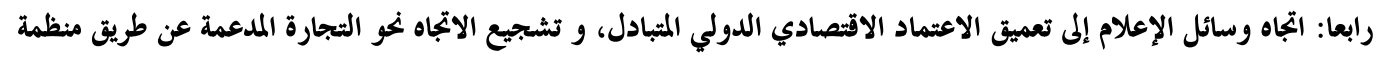

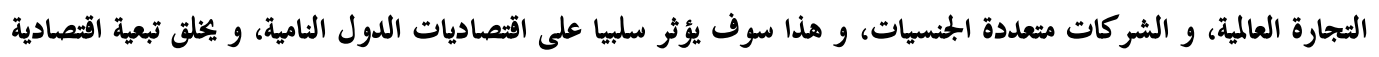
غربية، و يقضي على الاقتصاد الوطني للدول الصغيرة.

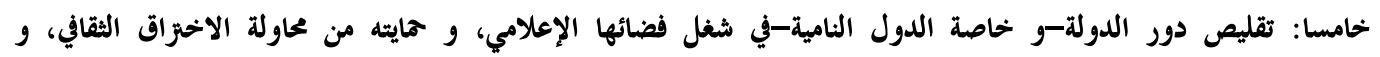

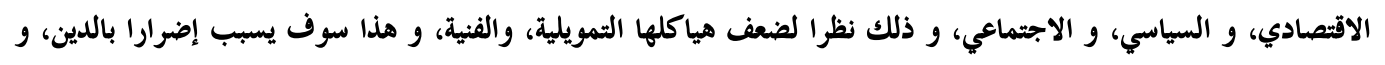

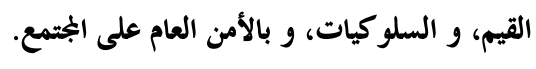

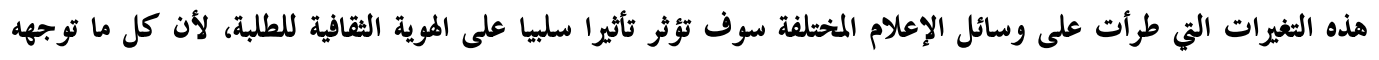

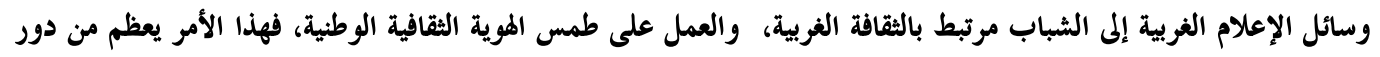
وسائل الإعلام المتعددة في تحقيق المنطلبات اللازمة لتحقيق الموية الثقافية للطبلة.

$$
\text { و عليه تتجلى سلبيات وسائل الإعلام على الموية الثقافية للطلبة فيما يلي: }
$$

أولا: تعد وسائل الإعلام استعمارا ثقافيا جديدا، لأنها تهدف إلى إحداث خلل في الهويات الثقافية للطلبة ، بنشر، وهيمنة الهوية

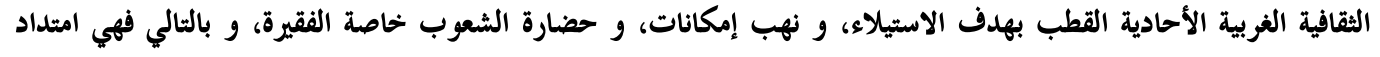




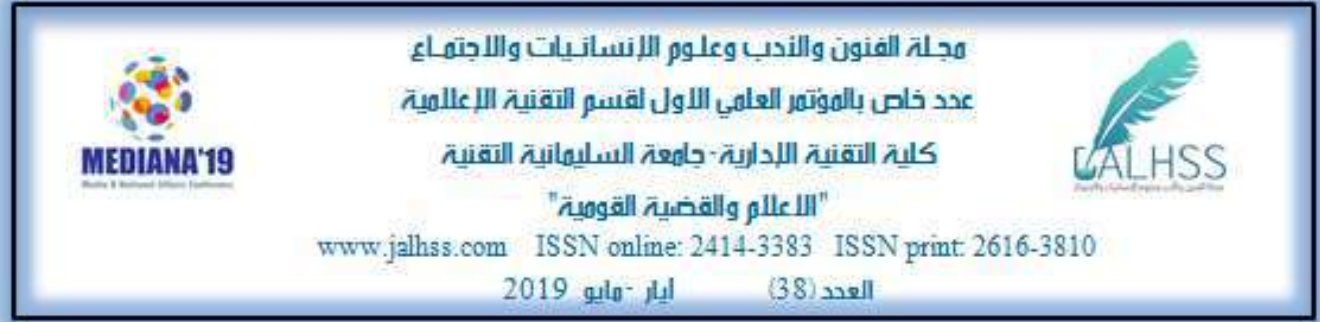

للاستعمار التقليدي الثقافي القديم، حيث كان الغزاة سابقا يسلبون مقومات الهوية، كاللغة، و الدين من أصحابها بطمس الشخصية،و الموية الثقافية لإخضاع المستعمرات، و ذلك باستغلال شبابها، و خحاصة التلاميذ منهم.

ثانيا: تعنى الهيمنة الثقافية لظاهرة وسائل الإعلام هيمنة النموذج الغربي على ثقافات الأمم باستهداف الثقافات الخلية، و الإقليمية بالزوال اعتبارا أن أخطر الغزو الثقافي ذو الوجه القديم، و الجديد لا زال قائما، و أشد شراسة ضد الثد الهوية الثقافية

ثالثا: تفرض وسائل الإعلام استراتيجية جزئية للإنسان، فهي تريد مسخ و نزع الروح من الجسد بإبقاء الجانب المادي، و

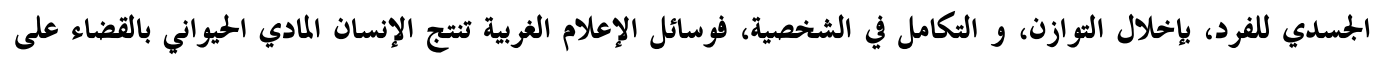

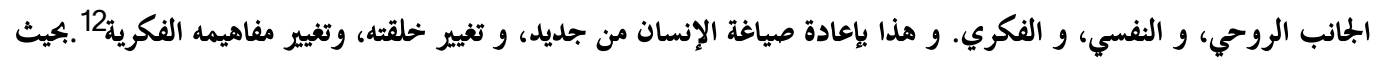
تتأسس الهوية الثقافية على حب الذات، والفردية بتحقير المعالم الشخصية للفرد، و الولاء للفكر المادي، و التبعية للثقافة المادية الغربية، التي لا تقيم وزنا للإنسانية، و ترسيخها في نفوس الطلاب.

فالهدف الحقيقي من العولمة الثقافية عبر وسائل الإعلام هو إبقاء التبعية بإبقاء أهم الشعوب،وخاصة منها المتدينة بالإسلام في درجة

عالية من التبعية الثقافية13.

فالتبعة الشاملة للغرب، و ضعف أداء الاقتصاد خاصة العربي منه، و فشل برامج التنمية الغلية لا يمنح فرصا لتشكيل هوية اقتصادية لتحصين الهوية الثقافية، لأن ما يتم استيراده من الغرب من منتجات، و آلات ليست منتجات فقط بل تلك قيم، و سلو كات غربية14.أي تلك المنتجات هي نتيجة للثقافة الغربية المصدرة، و المستثمرة.

حيث لم يحدث في التاريخ أن أقدم العالم على رموز، و سلع ثقافية استهلاكية، و شبابية كما هو عليه الحال اليوم، فالإقدام على العام هذه الثقافة الاستهلاكية، والثبابية من مأكولات، و شخصيات أفلامها تأتي من مصدر واحد موجودة تقريبا في كل العالم، مما يثير مدى موقف الثقافة الغحلية، و منها العربية في مواجهة الغزو الثقافي الغربي من مالئل

رابعا: تؤثر وسائل الإعلام على الهوية الثقافية من الناحية الاجثماعية للتلاميذ من خلال أنها مشروع غير أخلاقي، و مشروع

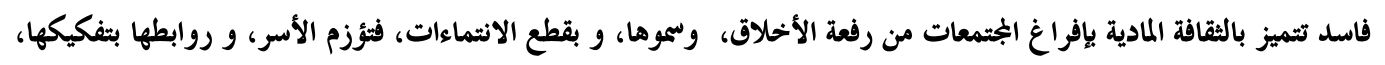

$$
\text { و بزرع المشاكل، و بث الانحراف، و لا مكانة لصلة الرحم، والنسب فيها. }
$$

إذ إن الثقافة الشعبية الغربية طفت على أذواق الطلاب من خحلال الملبس، و المأكل، و الموسيقى، ومشاهدة الأفلام، و استهلاك

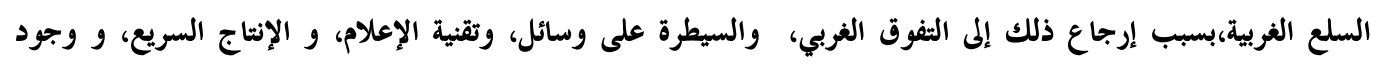
السوق المستهلكة بتصدير تلك المنتجات.

فالشمولية الثقافية تفرض نفسها خصوصا على الأفراد، و الأسر ببنود حقوق الإنسان، و وسائل الإعلام التي تسيطر عليها الدول

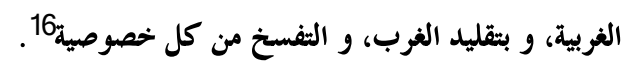




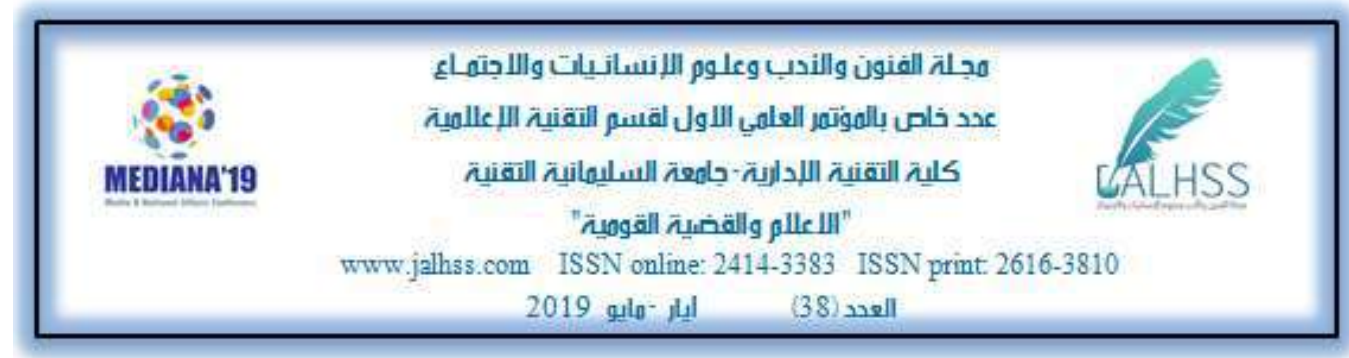

خحامسا: السيطرة على وسائل الإعلام الخركة للثقافة الغربية تهيمن عليها الدول التكنولوجية، والمثفوقة عسكريا، فالعالم الفقير ليس له القدرة في هذه الوسائل، و مواجهة الاكتساح الإعلامي الغربي مما يعني قصور العالم الفقير في ماية، و تجديد هويته الثقافية.17.

المبحث الرابع: بعض التطبيقات السلبية لوسائل الإعلام على الهوية الثقافية

$$
\text { الفرع الأول: اللغة و وسائل الإعلام }
$$

اللغة هي مقوم أساسي لأي أمة، و هي جهاز الاجتماع عند الإنسانه18، و هي الموقع في صياغة وحدة الأمة، فاللغة، و الأمة

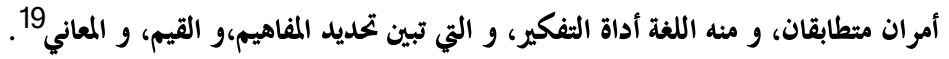

إذ إن العولمة الثقافية لا ترضى بوجود لغات أخرى غير اللغة الانكليزية مثلا، و هناك من المغالطات التي ترى أن اللغة العربية هي

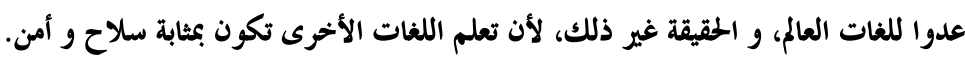
لكن لا يمكن أن تكون هناك لغة بمثابة ضرة او ند للغة أخرى،20خاصة في الدول المسلمة باعتبارها لغة القرآن، و التواصل بين مذه الدول.

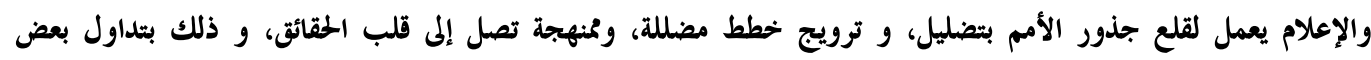

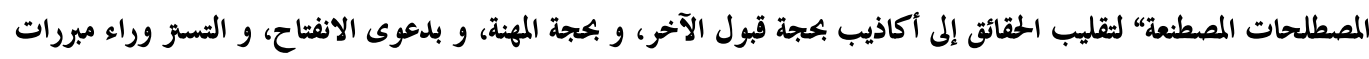

$$
\text { واهية } 21 .
$$

وخاصة أن اعتبار اللغة العربية التي تمثل أصل هوية الشعوب العربية أنها عدو، و منافس للحضارة الغربية، وبالثالي المواجهة بين الثقافة الإسلامية و الثقافة الغربية22.

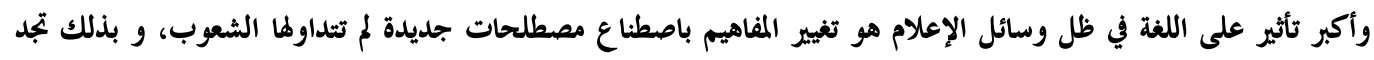

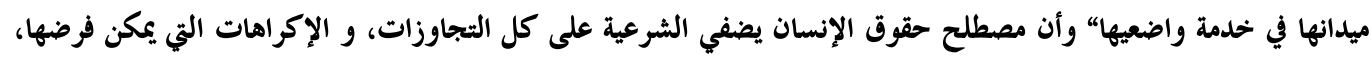
و ممارستها على الآخرين23.

واليوم يتم الاعراف باللغات الأجنبية كلغات أساسية تقريبا كاللغة الرسمية في الدولة، و توسيع الحجم الساعي لها، فأصبحت، و

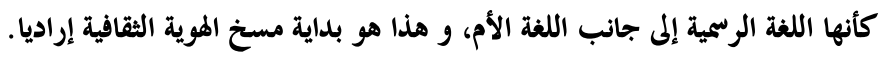

ولعل الثنافس بين الدول المتقدمة، و ربط الدول الاستعمارية بالدول المستعمرة في جانب إضفاء اللغة الأجنبية لتصبح لغة ذات

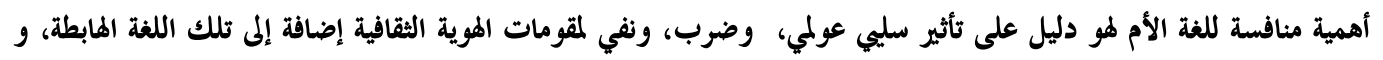




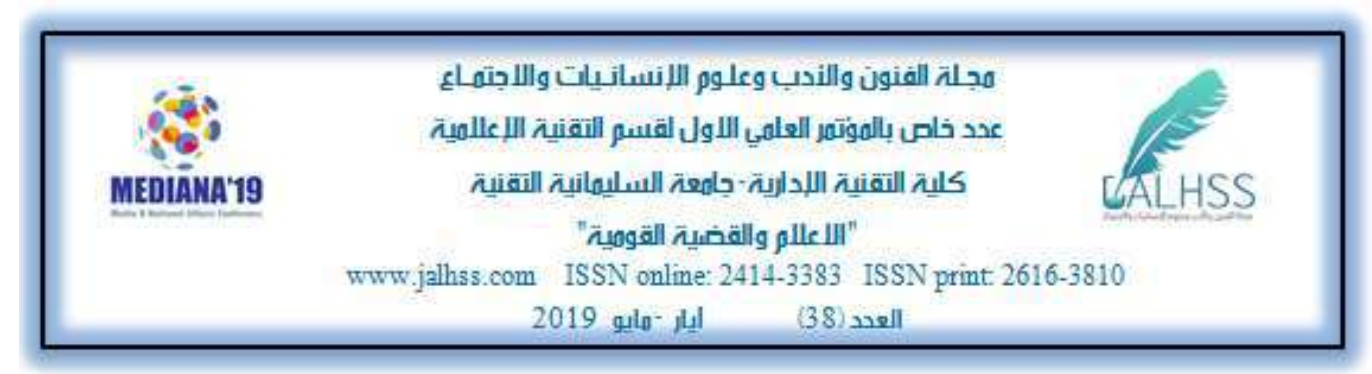

اللغة العامية التي تزايدت بفعل وسائل الإعلام من تداخل اللغات في بعضها البعض بإحداث لغة جديدة غريبة بالجمع بين عدة كلمات تمثل عدة لفات تؤثر سلبا على التحصيل الدراسي للمتعلم. الفرع الثاني: الدين و وسائل الإعلام

تستهدف وسائل الإعلام ديانة، و عقائد الطلبة ايضا، و لعل الميدان الحصب لوسائل الإعلام في المساس بحرية المعتقد، و الدين هو الحرب ضد معتني الشريعة الإسلامية او الديانات او الاقليات الاخرى، أو الحروب القائمة ضدهمومن أدلة ذلك وجود مصطلحات، وعبارات تبين ذلك، ومنها مصطلح " العولمة في حد ذاته، لأنه من وضع إنساني و إثارة بها النزاعات الداخلية، و

$$
\text { الحارجية للدول و مصطلح " الحرية " الذي يعني التحرر من كل قيد ديني. }
$$

الفرع الثالث: الزبية و وسائل الإعلام

تفرض وسائل الإعلام صياغة المناهج، و البرامج التعليمية في المدارس، و الجامعات، و المعاهد، و الكليات وفقا للتطور العالمي

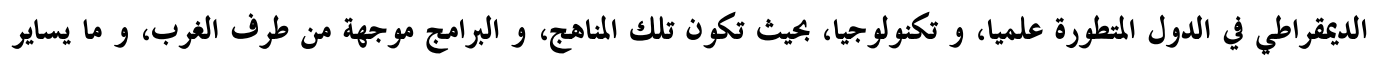
تطلعاته، و توجهاته، و يظهر ذلك في تصدير البرامج، و المناهج المختلفة، و التي تمس بالكيان الاجتماعي، و الثقافي للدولة، من حيث تغيير بعض مواد، أو مقاييس التدريس، كحذف مادة الزبية الإسلامية من البرامج الزبوية، والعلمية، و حتى في الجامعات، و يهدف هذا إلى تغيير ذهنية للطلبة تجاه الغرب أولا، و لنشر، و توسيع نطاق الهوية الثقافية الغربية خاصة في نطاق الدول الضعيفة.

حيث تسهر الدول الغربية على تصدير برابجها المختلفة، و التي سبق تصميمها قبلا، وبدراسة هادفة للمستقبل لتحقيق أغراضها السياسية، و الاجتماعية، و العلمية، بالقضاء على هوية، و مناهج،وعقلية الجُتمع الداخلي للدول، و الواقع يثبت أن دولا كثيرة تقوم باستيراد هذه المناهج، و البرامج بغية مسايرة العصر، و لكن هذا في حقيقة الأمر يهدف إلى سلخ الجتمع من مقوماته الأساسية، و إندماجه في فلك الهوية الثقافية الغربية ، في حين الدول الغربية لا يمكن لها أن تنسلخ عن مقوماتها الشخصية، و

الخحصوصية بل تريد ذلك لغيرها فقط.

و بهذا يحدث التعارض بين الأجيال في الدولة الواحدة من التأطي، و التوجيه، و التعليم في فترة اعتماد الدولة على خصوصيتها في الأول، واعتمادها على خصوصية البرامج المستوردة ثانيا، و منه يكون التناقض في البجتمع بين الجيل الكبير، والصغير، و ينتج عن هذا تغيير المنظومة الزبوية بتغييز المنظومة القانونية المؤطرة، و المنظمة لها.

$$
\text { الفرع الرابع: قلب موازين المشاعر و الحواس }
$$

إن الاختراع العبقري لوسائل الإعلام هو أن يرضينا حتى التخمة بالمظهر، و بعبارة أخرى أن يعيشنا باللاشيء، و ذلك من خحلال

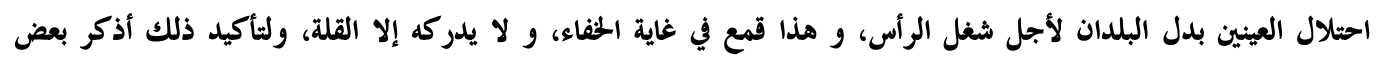

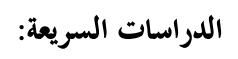




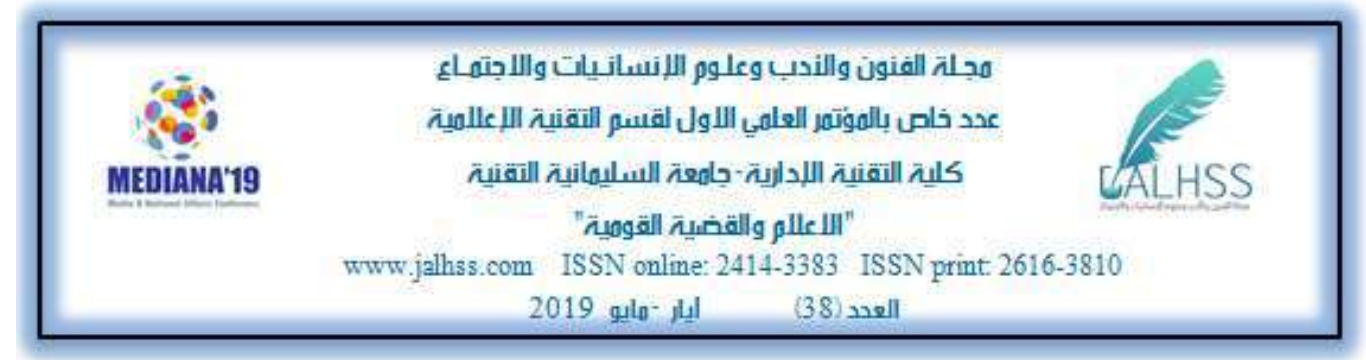

أولا: ارتفاع نسبة الفتيات غير الراضيات عن أجسادهن عند سن الثالثة عشر، و تتزايد هذه النسبة ارتفاعا عند السابعة عشر،

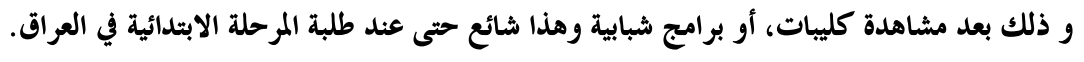

ثانيا: انتشار دائرة استخدام هرمونات النمو، فقد ذكر أحد الأطباء أن الكثير من الآباء قد أصبحوا مهووسين بقامة أبنائهم وهم صغار، و بكل الطرق التي يمكن أن تساهم في زيادتها.

ثالثا: تشير الدراسات الغربية إلى أن عدم الرضا عن المظهر الجسدي عند الذكور قد تضاعف إلى ثلاث مرات خحلال الثلاثين سنة الأخيرة.

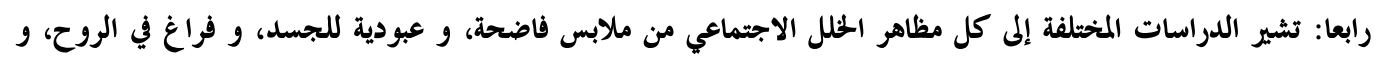

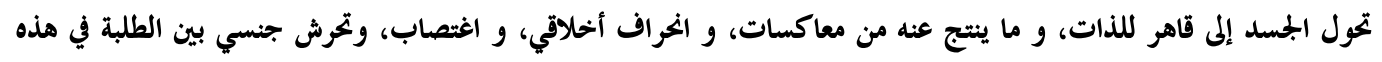

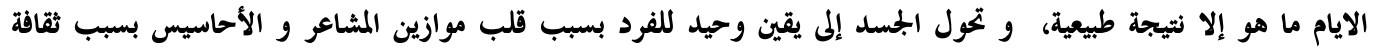

$$
\text { الصورة ( الجمسد ). }
$$

خامسا: أما على مستوى الطفل وقبل دخوله المرحلة الابتدائية فحدث و لا حرج، فالطفل يستخدم عينيه أكثر من حواسه

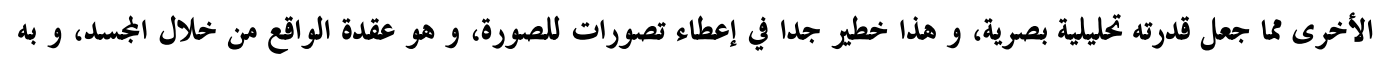
يصل تحطيم القيم، و أنماط سلوكية جديدة. الفرع الخامس: القراءة و وسائل الإعلام أولا: تؤكد الدراسات أن زمن القراءة للطفل في العراق لا تتجاوز ست دقائق في العام الواحد حسب تقرير الايسيسكو.

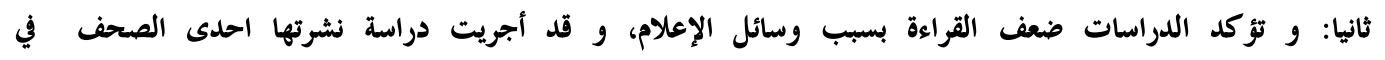

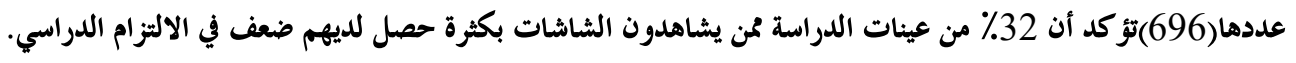

ثالثا: في كتاب(التنشئة الأسرية)محمد عباس نور الدين أكد فيه أن دراسات كثيرة أثبتت قلة الميل للقراءة بين الأطفال بسبب

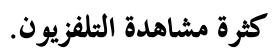




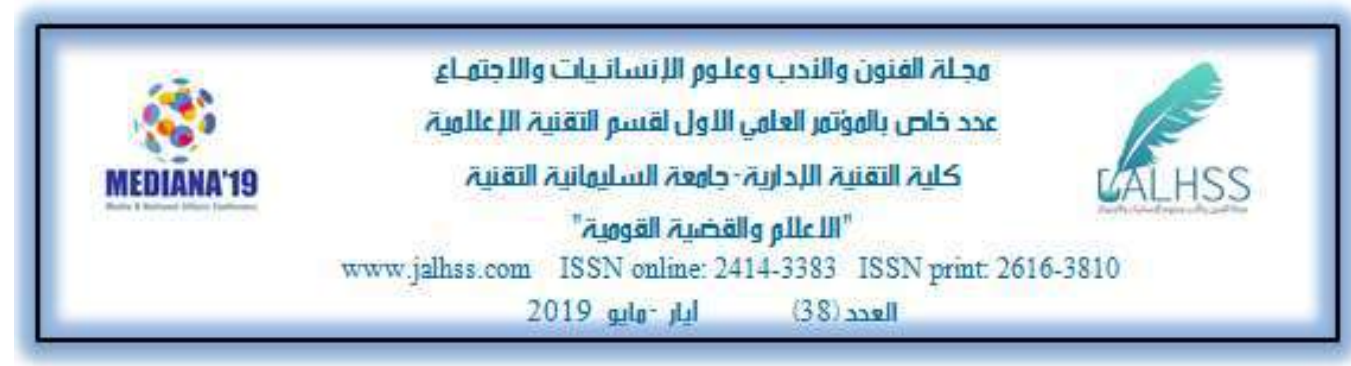

الاستنتاجات

وأخيرا يمكن القول إن الكلام عن الهوية الثقافية في وسط طلبة المرحلة الابتدائية في العراق يثير إشكالية وسائل الإعلام التي تمثل

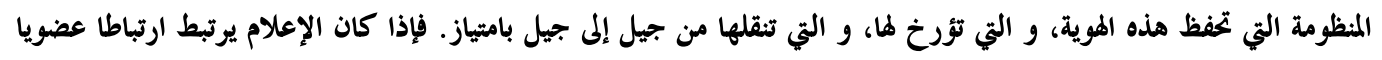

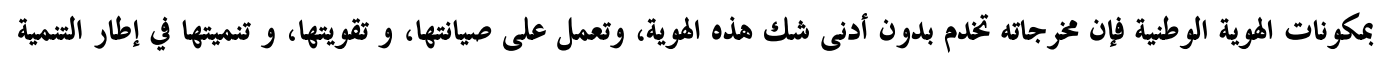

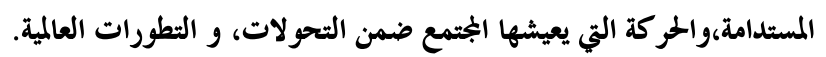

أما إذا كانت المنظومة الإعلامية مهزومة، و غير منتجة، و مستقبلة، و مستهلكة فقط فإنها بدلا من المساهمة في الحفاظ على الموية

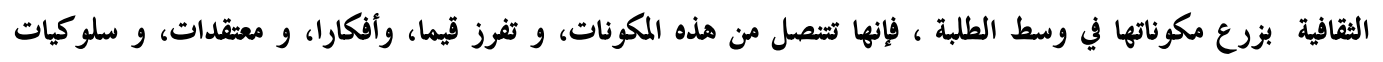

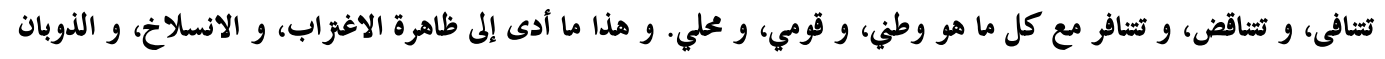

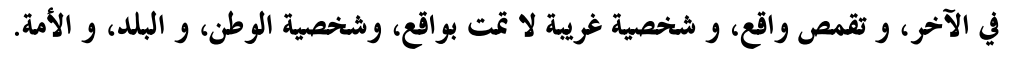

ولهذا يجب على المعلم أن يهتم بتطوير أربعة جوانب تعزز الانتماء الوطني لدى الطلبة، و وهي المعرفة، و القيم، و الميول،

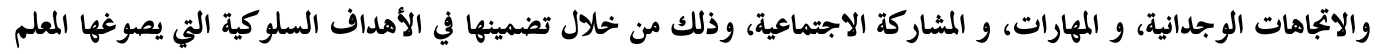

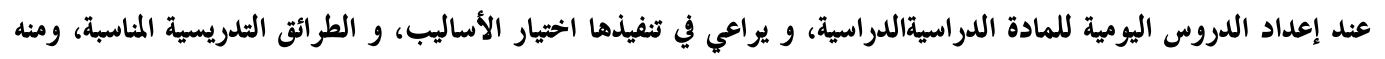
تبرز أهميته، و دوره في وصل هذه الأمة بامتدادها الحضاري.

فوسائل الإعلام ليست خحيرا كله، و ليست شرا كله، و إنما ينبغي على أي أمة أن لا تحدث قطيعة معها كي لا تكون منعزلة عن

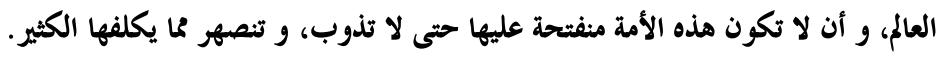

إنفا يجب أن تكون الأمة عالمية بمعنى أن تحافظ على كيانها، و هويتها الثقافية، و التفتح على الثقافات الأخرى، بالحفاظ على التها

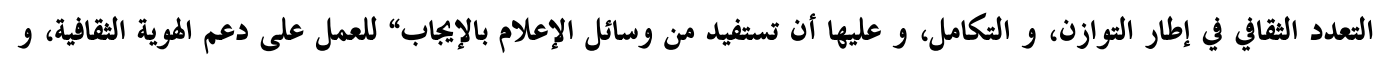
تثبيتها في وسط الطلبة.

\section{التوصيات}

في ضوء نتائج البحث و استناجاته توصي الدراسة بما يلي:

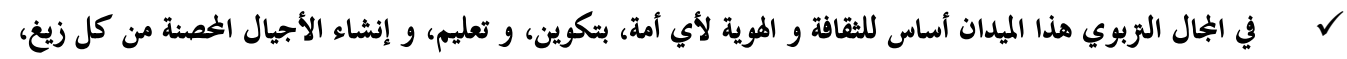

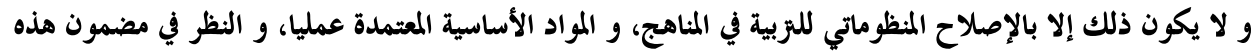

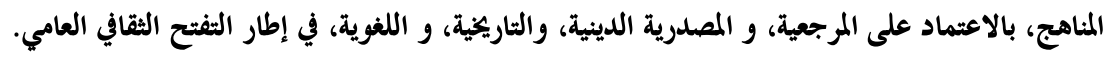

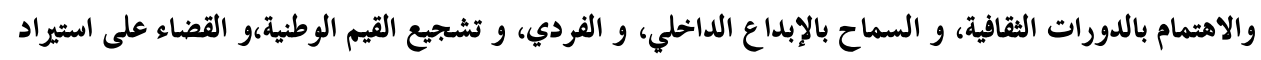

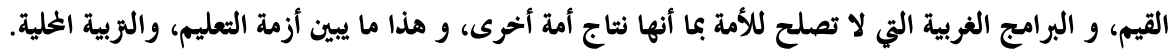




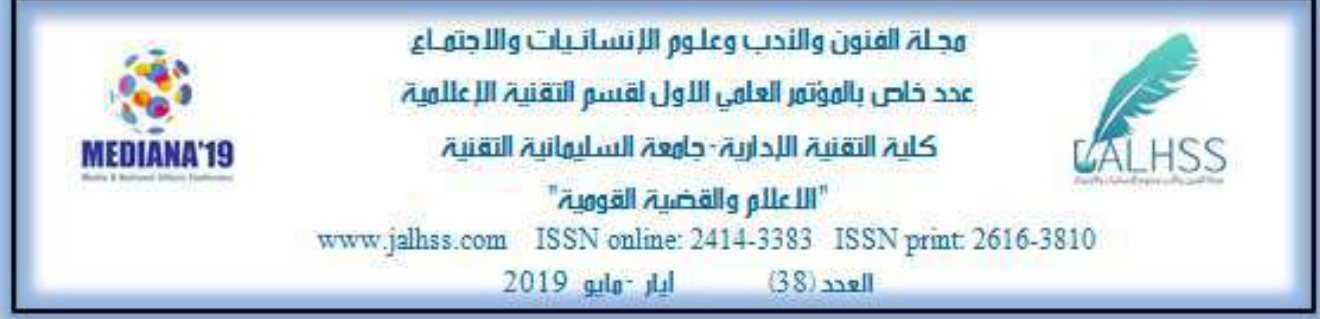

لا بد على المربين العاملين في ميدان الزبية والمشرفين على فاصل المرحلة الابتدائية من الوقوف، والتصدي لهذا العدوان التقني بالتحلي، و التمسك بالقيم الوطنية عن طريق الندوات، والملتقيات التثقيفية، و الأيام الثقافية في المؤسسات التبوية، و دور الثقافة، و المراكز الثقافية والعلمية، وغيرها من المنابر التي تحمي المتعلم في مدارسنا من خطر الذوبان في قوميات الآخر، و محاكاتها، و تقليدها من طرف بعض الشباب المتعلم في مدارسنا الابتدائية . ضرورة الامتمام بمقرراتومنهيجالماود الثدريسية للبة المرحلة الابتدائية من خلال اقتصار تدريسها على المعلمين المختصين، مع ضرورة التزام كل معلم بتدريس المقرر الذي يحمله تخصصه.

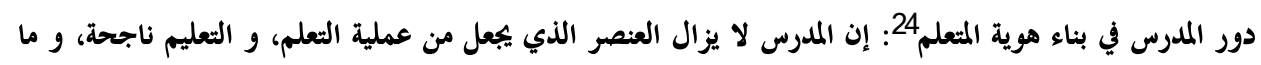
يزال الشخص الذي يساعد المثعلم على التعلم، والنجاح في دراسته، و مع هذا فإن دور المعلم اختلف بشكل جوهري

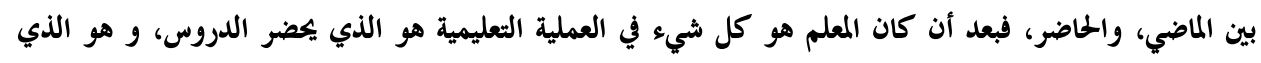
يشرح المعلومات، وهو الذي يستخدم الوسائل التعليمية، و هو الذي يضع الاختبارات والامتحانات لتقييم الطلبة التبات وادائهم التعليمي، فقد أصبح دوره يتعلق بالتخطيط، و التنيم، والإشراف على العملية التعليمية أكثر من كونه

$$
\text { شارحا لمعلومات الكتاب المدرسي. }
$$

حقا تغير دور المعلم تغييرا ملحوظا من العصر الذي كان يعتمد على الورقة، و القلم كوسيلة للتعلم والتعليم إلى العصر الذي يعتمد على الحاسوب، و الأنتزنت و هذا التغيير جاء انعكاسا لتطور الدراسات في مجال الزبية، و علم النفس، و علم النفس التعليمي بخاصة، و ما تمخضت عنه من نتائج و توصيات، حيث كانت قديعا تعتبر المعلم العنصر الأساسي، و تبعا لذلك في العملية التعليمية،والغحور الرئيسي لها، و لكنها الآن تعتبر المتعلم الغحور الأساسي، و تبعا لذلك فقد تحول الاهتمام من المعلم الذي كان يستأثر بالعملية التعليمية إلى المتعلم الذي تتمحور حوله العملية التعليمية، و ذلك عن طريق إشراكه في أذهان التلاميذ من خحلال (حب الوطن وغرس قيم التسامح بين الطلبة والتمسك بعباديء الوطن وقيمه وتاريخه والذود عن اللغة العربية و الدفاع عنها والمساهمة في عملية التوعية الثقافية من خحلال المشاركة في التظاهرات الفولكلورية و الاحتفالات الوطنية. كل مذه السلوكيات، و المظاهر الراقية تجعلنا في مصاف الأمم التي تحتزم هويتها، و تاريخها دون الإنقاص من ذواتنا، أو التخلي عن هويتنا، و ماضينا العريق، و ضرورة إعطاء مجتمعنا الاحترام الذي يليق به.

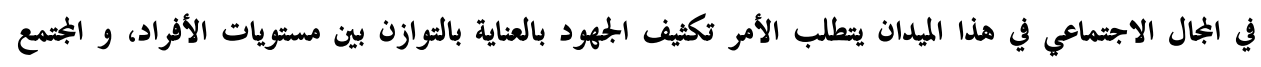
بتحقيق نظام يكفل مصلحة الأفراد في ظل مصلحة الجختمع، بالقضاء على الحرية الفردية التي تبغيها العولمة، و دعم

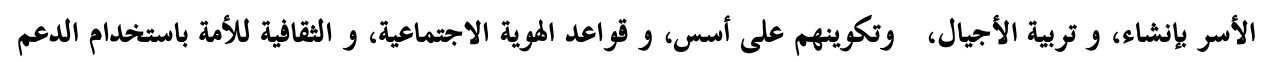
المالي للأسر، و الإعلامي لنشر ثقافة الحفاظ على الهوية، و التنشئة الأساسية للهوية الثقافية. ضرورة إشراك منظمات الجتمع المدني، و المؤسسات الزبوية التي تنشط في الغحافظة على القيم الوطنية، تساهم في إبراز تاريخ، و عاداتنا، و تقاليدنا . أن يحظى موضوع الهوية الثقافية ،و الحفاظ عليها بأهمية خاصة من مؤلفي كتب الدراسات الاجتماعية لمرحلة التعليم الابتدائي كونها تمثل الحدث الأهم، و الأبرز. 


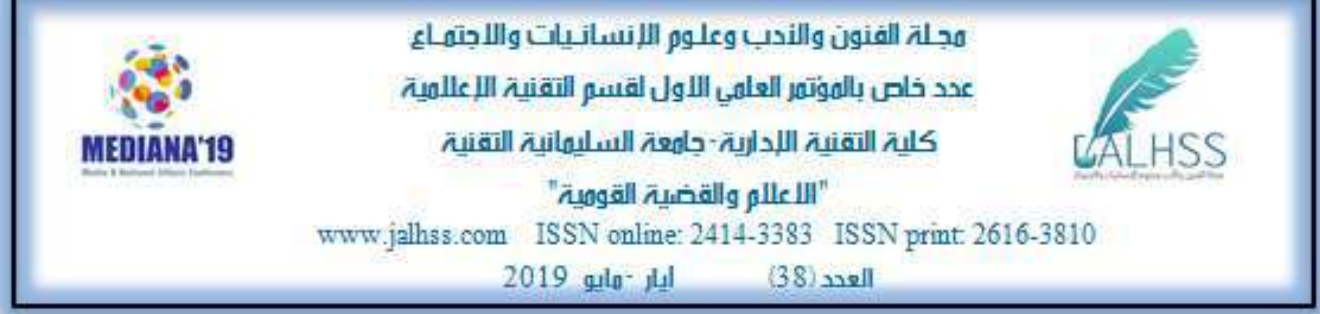

ضرورة التنسيق بين الجهات، و المؤسسات المسؤولة عن تنشئة الأطفال في البيت،والمدرسة، والبجتمع، و وسائل الإعلام للعمل على غرس الهوية الثقافية للطلبة.

ل العناية الحاصة بالبرامج، والمسلسلات، والأفلام المعدة للأطفال من قبل القائمين على القنوات التلفزيونية، لما لها من

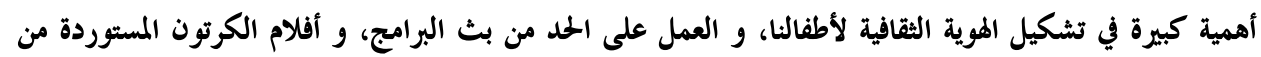
ثقافات أخرى، و تهذيبها لتناسب ثقافنتا العربية الإسلامية التي ترفض العنف. الاستفادة من وسائل الإعلام في مجالها الإعلامي، و التقني، و الاتصالاتي، و ذلك بجلب التكنولوجيا، واستخدامها في لئ أغراض من شأنها حفظ الهوية الثقافية، دون المساس سلبا بخصوصية هذه الهوية. يبب التحرك لإبراز الهوية الثقافية، دون البقاء مكتوفي الأيدي، و انتظار الغزو الثقافي الغربي من أجل استهلاكه، و الاعتراف به، و دون شروط تفرض نفسها من الموية الثقافية الخلية. الاعتبار بالغير“ فالصين، و اليابان باعتمادهما على اللغة الوطنية كأساس لمنطلقهما في الثورة العلمية، و التقنية، و و التكنولوجية، والاقتصادية فيما يعبر عن حاجات أفرادها، و التي جمعت شمل الأمة استنادا إلى اللغة.

المصادر والهوامش

1 - الطلبة مصطلح مشتق من كلمة لاتينية Scholaris، و كانت تعني في القرون الوسطى الطالب، و تعني حاليا الطفل الذي يرتاد المدرسة باستمرار. 2- د.أسعدالسحمراني، ويلات العولمة على الدين و اللغة و الثقافة، دار النفائس، الطبعة الأولى، 2002، ص:82. 3-د.زغو محمد، أثر العولمة على الموية الثقافية للأفراد و الشعوب، الأكاديية للدراسات الاجتماعية و الإنسانية، الطبعة

الرابعة، 2010،ص: 93. 4-د.خالد بن عبد الله القاسم، العولمة و أثرها على الهوية(1/2)، 2006، على الموقع : WwW.islamtoday .net

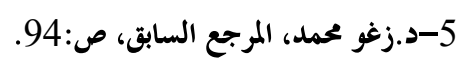
6 6- د.زغو محمد، المرجع السابق،ص: 94

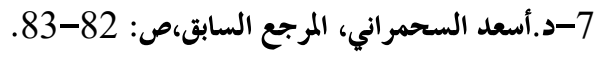
8-دور الإعلام في تحقيق متطلبات الأمن الثقافي،ي: htt//uqu.edu.sa/control/add_menu/ar/ 4300368

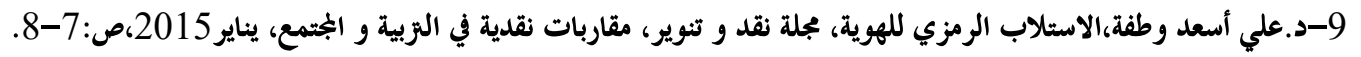

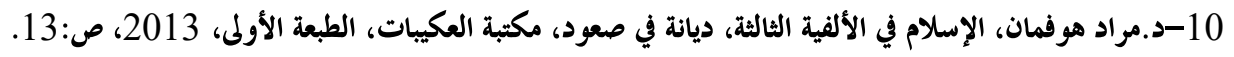
11 1-دور وسائل الإعلام في تحقيق الأمن الثقافي، في: .oumqora .org .ouWw 12-د.محمد بن سمينة، العولمة و آثارها على الثقافة الإسلامية في الجزائر، مجلة الثقافة الإسلامية، السنة الثانية، العدد الثاني، 2006، ص:80-79 


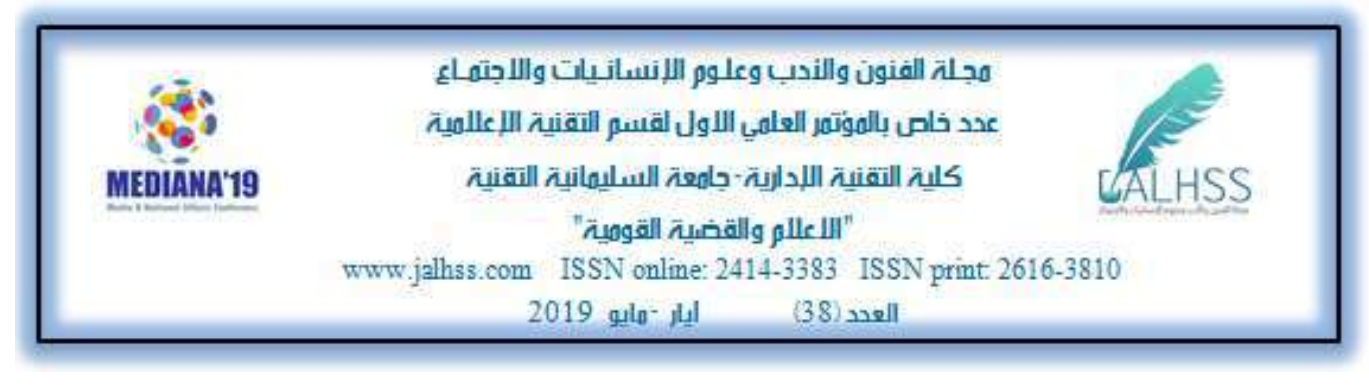

13-د. أسعد السحمراني، المرجع السابق، ص:09.

14-أ. بوتخيل معطي، أهم تحديات الأسرة والرهانات المطروحة، مجلة الثقافة الإسلامية، السنة الأولى، العدد التجريي، 2005، ص:145.

15-د.نبيل علي، العرب و عصر المعلومات، عالم المعرفة، الكويت، العدد 1454،1944.184.

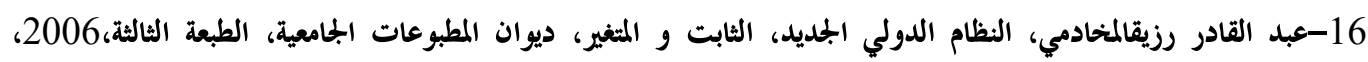
ص:66-67.

17-1 أ. بوتيل معطي، المرجع السابق،ص:144-14-14.

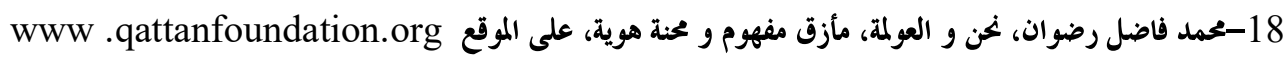

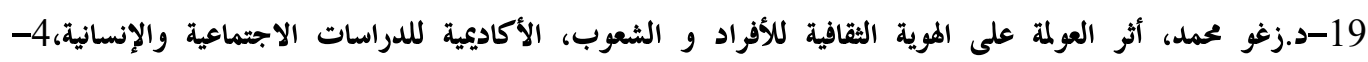
2010،ص:98-99.

20-د.أسعد السحمراني، المرجع السابق،ص:87. 2010.

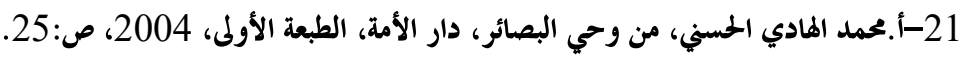

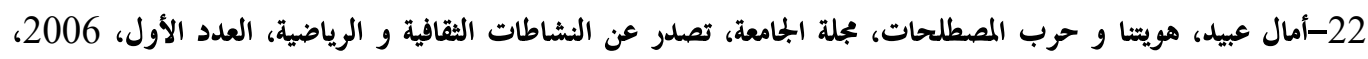
ص:12.

23-أ.عبد العزيز بوسالم، مل تموت الثقافة الوطنية في زمن العولمة، مجلة آفاق، العدد الحخاص بالعولمة الاقتصادية، ،ص:18. 24-أ. بوتخيل معطي، المرجع السابق، ص:146. 